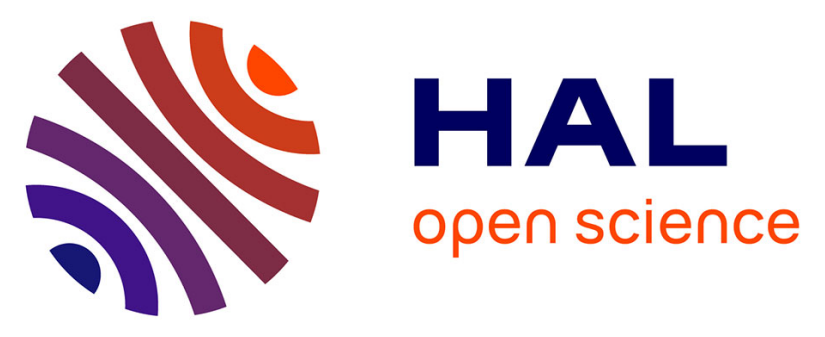

\title{
Listeria monocytogenes -associated endovascular infections: A study of 71 consecutive cases
}

Michka Shoai-Tehrani, Benoit Pilmis, Mylène M Maury, Olivier Robineau,

Olivier Disson, Grégory Jouvion, Gabrielle Coulpier, Pierre Thouvenot, Hélène Bracq-Dieye, Guillaume Vales, et al.

\section{To cite this version:}

Michka Shoai-Tehrani, Benoit Pilmis, Mylène M Maury, Olivier Robineau, Olivier Disson, et al.. Listeria monocytogenes -associated endovascular infections: A study of 71 consecutive cases. Journal of Infection, 2019, 79 (4), pp.322 - 331. 10.1016/j.jinf.2019.07.013 . pasteur-02448284

\section{HAL Id: pasteur-02448284}

https://hal-pasteur.archives-ouvertes.fr/pasteur-02448284

Submitted on 26 Aug 2020

HAL is a multi-disciplinary open access archive for the deposit and dissemination of scientific research documents, whether they are published or not. The documents may come from teaching and research institutions in France or abroad, or from public or private research centers.
L'archive ouverte pluridisciplinaire HAL, est destinée au dépôt et à la diffusion de documents scientifiques de niveau recherche, publiés ou non, émanant des établissements d'enseignement et de recherche français ou étrangers, des laboratoires publics ou privés.

\section{(1) (1) $\$$}

Distributed under a Creative Commons Attribution - NonCommercial - NoDerivatives 44.0 


\section{Listeria monocytogenes-associated endovascular infections: a study of 71 consecutive cases}

Michka Shoai-Tehrani ${ }^{1,2}$, Benoit Pilmis ${ }^{1,2}$, Mylène M. Maury ${ }^{1,3,4}$, Olivier Robineau ${ }^{5}$, Olivier Disson ${ }^{1,4}$, Gregory Jouvion $^{6}$, Gabrielle Coulpier ${ }^{1,3}$, Pierre Thouvenot ${ }^{1,3}$, Hélène Bracq-Dieye ${ }^{1,3}$, Guillaume Valès ${ }^{1,3}$, Alexandre Leclercq ${ }^{1,3}$, Marc Lecuit ${ }^{1,2,3,4 *}$ and Caroline Charlier ${ }^{1,2,3,4 *}$ for the Listeria endovascular infections study group

\footnotetext{
${ }^{1}$ Institut Pasteur, French National Reference Center and WHO Collaborating Center for Listeria, Paris-France

${ }^{2}$ Université de Paris, Hôpital Universitaire Necker-Enfants Malades, Service des Maladies Infectieuses et Tropicales, Institut Imagine, Paris-France

${ }^{3}$ Institut Pasteur, Biology of Infection Unit, Paris-France

${ }^{4}$ Inserm U1117, Paris-France

${ }^{5}$ Centre Hospitalier Universitaire Tourcoing, Tourcoing-France

${ }^{6}$ Institut Pasteur, Experimental Neuropathology Unit, 75015 Paris-France
}

\section{Highlights:}

- Endovascular listeriosis is a rare but severe form of invasive listeriosis.

- It mostly reported in older patients with prosthetic devices.

- Listeriosis endocarditis is associated with a $41 \%$ mortality.

Running title: Listeria monocytogenes and endocarditis and vascular infections

* These authors share senior authorship

Correspondence: caroline.charlier@pasteur.fr and marc.lecuit@pasteur.fr, Unité de Biologie des Infections, Institut Pasteur, 28 rue du Dr Roux, 75015 Paris, France. Phone: +33 1406134 20, Fax: +33140613421

Word count: 2929 words 


\section{ABSTRACT}

Background: Listeria monocytogenes-associated endovascular infections are not well characterized.

Methods: Retrospective study of 71 culture-proven cases reported to the French National Reference Center for Listeria from 1993 to 2018.

Results: Seventy-one cases were identified: 42 with vascular aneurysms/prosthetic infections, 27 with endocarditis, 2 with both. Fifty-eight were men (82\%); median age was 75 years [46-92]; 93\% reported co-morbidities (66/71), including 50\% with immunosuppressive conditions. Vascular infections consisted of infected aneurysms (68\%) or prosthetic graft infections $(32 \%)$; vascular rupture was reported in 25/42 (60\%). Tissue samples grew L. monocytogenes in $98 \%(43 / 44)$ and blood cultures in $64 \%$ (27/42). Endocarditis cases involved prosthetic or native valves or intracardiac devices in respectively $62 \%(18 / 29), 28 \%(8 / 29)$ and $10 \%(3 / 29)$. Infected valves were aortic $(62 \%, 16 / 26)$, mitral $(31 \%, 8 / 26)$ or both $(8 \%, 2 / 26) ; 38 \%$ patients required surgery; $45 \%$ displayed heart failure; $17 \%$ had concomitant neurolisteriosis. In-hospital mortality in vascular infections was $12 \%(5 / 42)$ and $41 \%$ (12/29) for $L m$-associated endocarditis.

Conclusions: Endovascular listeriosis is a rare but severe infection. It manifests as vascular infections and endocarditis, mostly in older patients with vascular or cardiac valve prosthetic devices and comorbidities. Mortality in $\mathrm{Lm}$-associated endocarditis is twice higher than with other pathogens, requiring prompt recognition and treatment.

Keywords: listeriosis, Listeria monocytogenes, endocarditis, aneurysm, prosthesis 


\section{INTRODUCTION}

Listeria monocytogenes $(\mathrm{Lm})$ is a facultative intracellular Gram-positive bacterium responsible for listeriosis, a severe foodborne infection that mostly occurs in immunocompromised patients. The incidence of invasive listeriosis is estimated around 4-5 cases per million persons in the United States and in Europe (1). Three main forms are described: septicemia (S), central nervous system (CNS) and maternal-neonatal (MN) infections. Lm may also cause focal infections, which likely occur upon subclinical systemic dissemination. They include urinary, ocular, bone and joint, biliary tract and skin infections (2-6). Endovascular infections have also been reported. Altogether, 72 case reports of Lmassociated endocarditis related to have been reported worldwide since 1955, along with 47 cases with $L m$-associated vascular infections (7-18). There are reviews compiling these heterogeneous cases, but the clinical presentation, treatment and outcome of $L m$-associated endovascular infections remain unclear $(8,14,19)$. There are no therapeutic recommendations and no clinical trial has been performed. The increasing incidence since the mid 2000's of septicemic listeriosis in older patients, who are also more prone to develop aneurysmal infections and endocarditis, raises the possibility that the incidence of endovascular listeriosis may increase in this at-risk segment of the population (1).

We undertook a comprehensive retrospective survey over a 25 -year period to review all cases prospectively referred to the national surveillance system of listeriosis in France since its implementation. Seventy-one cases were identified and analyzed. We characterized the epidemiological, clinical and microbiological features of endovascular listeriosis and identified variations in presentations with regards to $L m$-bacteremia, endocarditis and vascular infections related to other pathogens. 


\section{PATIENTS AND METHODS}

Data collection - Surveillance of human listeriosis in France is based on mandatory reporting of cases to Santé Publique France since 1999 and voluntary submission of $L m$ strains to the National Reference Center for Listeria (NRCL) (20). The exhaustiveness of this reporting is estimated by capture-recapture at least 87\% (1). All cases declared between January 1999 and June 2018 with mention of "endovascular infection", "aneurysm" “aneurysmal infection", "cardiac device" "pace-maker", "vascular device”, "endocarditis", "infected thrombus" and "endovascular infection" were included. In addition, all patients with similar mentions whose strains had been sent to the NRCL between 1993 and 1999, before the mandatory reporting era, were also included. No case of myocarditis was identified.

Clinicians and microbiologists in charge of the patient were all contacted to collect additional data according to a standardized questionnaire of epidemiological, clinical and biological treatments and follow-up parameters. Because of the observational nature of this study, our local ethical Committee (Comité de Protection des Personnes Ile de France 8) did not request formal Institutional Review Board approval according to the French legislation.

Case definition - A case was defined as:

Vascular infection due to Lm when $\mathrm{Lm}$ demonstrated by culture of resected material, either prosthetic vascular device, aneurysmal tissue or perivascular collection, or in case of clinical, radiological and per-operative findings compatible with vascular infection and $\geq 1$ positive blood culture for $\operatorname{Lm}(21,22)$. Endocarditis due to $L m$ when $\geq 1$ positive blood culture yielded $L m$ with echocardiogram evidence for endocarditis (cardiac abscess and/or of cardiac vegetation(s) responsible for embolism(s) and/or new partial dehiscence of prosthetic valve and/or other evocative image(s) on a prosthetic device), or when Lm was demonstrated by culture of a vegetation/valve (adapted from $(23,24)$ ).

All patients with endocarditis underwent echocardiography and presented with criteria that fulfilled the modified echocardiographic Duke's criteria for infective endocarditis (23).

Characterization of $\mathbf{L m}$ isolates - Characterization of all $\mathrm{Lm}$ isolates was performed in the context of epidemiological surveillance of listeriosis. For species identification of isolates collected before January 2017, we used the API-Listeria identification microgallery (bioMérieux, Marcy l'Etoile, France). For isolates 
collected after January 2017, MALDI-TOF mass spectrometry was performed using a microFlex LT/SH MALDI-TOF MS instrument (Bruker Daltonics) as previously described (25). The MALDI BioTyper (MBT) compass explorer software v4.1.60 (Bruker Daltonics, Bremen, Germany) was used for spectra analyses and comparison with the MALDI BioTyper Reference library (database [DB-5989] MS; Bruker Daltonics) for automatic species identification. API-Listeria or MALDI-TOF mass spectrometry were combined to hemolysis test on horse blood agar and incubated 24 hours at $37^{\circ} \mathrm{C}(26)$. Genome sequencing was performed as previously described (27). Multilocus sequence typing (MLST) clonal complexes (CCs) (28), PCR serogrouping (29) and core genome MLST (cgMLST) profiles (30) were deduced from genome assemblies using the BIGSdb-Lm platform (http://bigsdb.pasteur.fr/listeria).

Histological analyses - Four $\mu$ m thick sections of paraffin-embedded tissue samples were stained with hematoxylin-eosin (HE). Lm was labeled by immuno-histochemistry (IHC) using a polyclonal rabbit antiserum that detects $L m$ serotype 1a/b (Listeria O I/II antiserum Seiken kit; Denka Seiken Co., Tokyo, Japan) and a goat anti-rabbit antibody coupled to peroxidase (EnVision+, Dako), followed by hematoxylin counterstaining. Images were captured with the cellSense software on an Olympus IX81 microscope equipped with an x100 objective.

Statistical analyses - Statistical analyses were performed with R software (version 3.4.0). Continuous variables were compared using the non-parametric Mann-Whitney rank sum test. $\mathrm{Chi}^{2}$ square and Fisher exact test were used to assess significant relationships between discrete variables. A $P$ value $<0.05$ was considered significant. To assess the odds ratio (OR) of endovascular listeriosis in patients with prosthetic devices and bacteremia, patients diagnosed with septicemia in the whole MONALISA cohort with septicemia were analyzed with regards the diagnosis of endovascular infection and the presence of valve, intracardiac or intravascular device (31).

MONALISA is a prospective national study implemented in France in 2009, compiling all microbiologically-proven cases of invasive listeriosis in France, including $\mathrm{Lm}$-septicemia, and neurolisteriosis (31). 


\section{RESULTS}

Clinical cohort - Among the 7,294 human strains collected between 1993 and July 2018 and retrieved from non-maternal-neonatal infections, 71 were $L m$-associated endocarditis or vascular infections, representing $1 \%$ of non-maternal infections gathered for this period: 42 patients had vascular listeriosis (58\%), 27 patients had endocarditis and 2 patients had both.

Epidemiology - Epidemiological features are detailed in Table 1. Patients were mostly older men. Sixty patients were older than 65 years (85\%). All but 5 (66/71,93\%) reported at least one comorbidity. Cardiovascular disease was the most frequently reported comorbidity (53/70, 76\%), including hypertension $(n=19,27 \%)$, coronary artery disease $(n=16,23 \%)$, previously identified degenerative native valve disease (all reported in patients with endocarditis, $n=13 / 29,44 \%$ ), lower limb arteriosclerosis obliterans $(10 / 70,14 \%)$, previously identified aneurysms (all reported in patients with vascular infections, $9 / 44,20 \%)$ and atrial fibrillation $(9 / 70,13 \%)$. No congenital heart susceptibility to endocarditis was reported. Other non-immunosuppressive conditions included chronic obstructive pulmonary disease $(n=4,6 \%)$, gastroesophageal reflux disease $(n=3,4 \%)$, Parkinson's disease, gout attack and thrombophilia ( $\mathrm{n}=2,3 \%$ each), psychosis, asthma, renal lithiasis and epilepsy $(\mathrm{n}=1,1 \%$ each). Immunosuppressive conditions were found in 50\%. Altogether, heart or vascular prosthetic devices were reported in 33/71 (46\%) patients with endovascular infections, as compared to only 50 patients with septicemia out of the 427 septicemic patients from the MONALISA cohort (12\%) (31). Of these latter 50 patients, nine $(18 \%)$ were diagnosed with endovascular infection. The OR for $L m$-associated endovascular infection in patients with valvular/intracardiac/vascular device and concomitant $\mathrm{Lm}$ septicemia from the MONALISA cohort was calculated: 10.3 (95\% confidence interval [2.1-53.6], $\mathrm{p}=0.001)$

Clinical characteristics - They are detailed in Tables 2 and 3 (the clinical features of the 2 patients with endocarditis and vascular infection are described in both tables).

Vascular infections involved native aneurysms in 30/44 (68\%) and prosthetic tubes in 14/44 (32\%), with endovascular and extra-cavitary vascular infections diagnosed in respectively 6 and 8 of the 14 patients 
carrying synthetic vascular graft (Table 2). The time interval between graft placement and vascular listeriosis was above 1 year in all cases. Vascular infections involved the supra-renal aorta in 4/44 cases (9\%). They were acute (time interval between first symptom and diagnosis $<3$ days) in 9/44 cases (21\%). Clinical data were available for 42 cases and did not differ between native artery or endograft infection (data not shown). Local pain (abdominal, dorsal or limb) was the most frequent symptom, reported in 59\% (25/42). Other symptoms included limb ischemia $(n=5)$, diarrhea, local fistula $(n=2$, each) and adjacent L2-L3 vertebrae spondylodiscitis $(n=1)$. Nineteen patients $(19 / 39,49 \%)$ were afebrile. Three patients were asymptomatic, with vascular infection only suspected on the basis of an inflammatory syndrome and evocative radiological features (see below). Twenty-five patients (25/42, $60 \%)$ had evidence of vascular rupture, either contained $(n=19)$ or massive $(n=6)$.

The 29 endocarditis infections involved prosthetic valves in $62 \%(18 / 29)$, native valves in $28 \%(8 / 29)$ and intracardiac devices in 10\% (3/29, including 2 pace-makers and one ventricular assist device). Infected valves were aortic $(16 / 26,62 \%)$, mitral $(8 / 26,31 \%)$ or both $(2 / 26,8 \%)$. Concomitant neurolisteriosis was diagnosed in 5 patients $(5 / 29,17 \%): 3$ had brain abscesses and 2 meningitis, including one for whom $L m$ grew from CSF culture. One patient developed septic arthritis. No other septic dissemination was reported. No splinter hemorrhage, Janeway lesion, Roth's spots or Osler's nodes were evidenced.

Radiological findings - All patients with vascular infection had an imaging procedure performed. Images compatible with infection were reported in 10 cases and included intravascular heterogeneous thrombus $(n=4,15 \%)$, and/or contrast enhancement of the vascular wall $(n=5,13 \%)$ and/or periprosthetic collection and/or aneurysm at the site of graft anastomosis $(n=3,8 \%)$ (Figure 1).

Detailed echography data were reported in 27 cases. Twenty-six patients $(26 / 27,96 \%)$ had major criteria for endocarditis, with typical oscillating valvular vegetation $(n=17)$ and/or cardiac abscess $(n=7)$ or prosthetic valve dehiscence/ new paravalvular regurgitation without vegetation or abscess $(n=3)$. One remaining patient had a thrombus on his mono-ventricular assistance device, that was retained as a minor criterion for endocarditis in the context of concomitant fever, inflammatory syndrome and $\mathrm{Lm}$ documentation on this thrombus (Table 3). 
Laboratory features -Lymphopenia (lymphocyte count $<1000$ cells $/ \mathrm{mm}^{3}$ ) was reported in $15 / 36$ (42\%) patients (10/21 (48\%) and 5/15 (33\%) patients with vascular infections and endocarditis, respectively). C-reactive protein level $<20 \mathrm{mg} / \mathrm{L}$ was only reported in one patient with vascular infection. The relevant laboratory features are summarized in Tables 2 and 3.

Microbiological data - All infections were culture-proven, and the 71 strains were analyzed in the NRCL. Microbiological features are detailed in Tables 2 and 3. One patient with aneurysmal infection was infected with an avirulent Listeria species, Listeria innocua, evidenced in a per-operative sample. All others had L. monocytogenes collected.

Blood cultures: Blood cultures were performed in all patients with endocarditis and in 27/42 (64\%) patients with vascular infections. They were positive in $26 / 29(90 \%)$ patients with endocarditis, and in $10 / 27$ patients (37\%) with vascular infections, including 5 who were reportedly afebrile $(5 / 10,50 \%)$.

Molecular analysis: The biodiversity of clinical isolates was similar in patients with vascular infections and endocarditis, and mirrored the diversity of human clinical isolates collected in the NRCL in the same period with hypervirulent $L m$ clones (namely clonal complexes (CC1, CC2, CC4 and CC6) isolated in $42 \%$ of cases (30/71) and hypovirulent clones (CC9 and CC121) reported in 3\% (2/71) (32) (Figure 2 and Table S1).

Histological analysis - Mitral valve histopathology and immunohistochemical detection of $L m$ were performed (Figure S2). Valvular endocarditis was confirmed, characterized by multifocal inflammatory infiltrates with fibrin and calcification (Figure 3A-B). $L m$ was detected in the fibrin, using anti- $L m$ IHC (Figure 3C-D).

Treatment - Treatments are detailed in Table 4. All patients with vascular infections benefited from surgery, along with 11/29 (38\%) patients with endocarditis. Data regarding antibiotic therapy were available in 68/71 patients (96\%). One patient with endocarditis died within hours after blood sampling, before any antimicrobial therapy could be started. All others $(67 / 68,99 \%)$ received at least one antibiotic 
active against Listeria, including B-lactam in $61 / 68,90 \%$ of cases. Fifty-six patients $(56 / 67,84 \%)$ received a bi-therapy, that was administered $>5$ days in 34/51 (67\%, data not available for 5 patients).

Amoxicillin + aminoglycoside (gentamicin, $n=32$, netilmicin, $n=4$, or amikacin, $n=2$ ) was the most frequent combination antimicrobial therapy initiated, administered in 21/25 (84\%) patients with endocarditis and in 17/31 (44\%) patients with vascular listeriosis. Other combinations are detailed in Table 4. In 16/56 cases (29\%), initial amoxicillin/gentamicin therapy was switched after a median time of 3 days (range, 3-21 days), most frequently to combined oral amoxicillin + cotrimoxazole (10/16, $63 \%)$.

Outcome - In-hospital mortality data are presented in Tables 2 and 3. It was available for all but 2 patients with vascular infection $(69 / 71,97 \%)$. Mortality rate was significantly higher for endocarditis than for vascular infections $(12 / 29,41 \%$ versus $5 / 42,12 \%, p=0.009)$ and remained stable over time (data not shown). Median time to death was 19 days (range [5-44]) for patients with vascular infections and 19.5 days (range [8-75]) for those with endocarditis. Neither time interval from first symptom to diagnosis, nor report of an immunosuppressive comorbidity, isolate genotype, number of positive blood cultures, surgery procedure, or antimicrobial therapy regimen (mono- versus bi-therapy, aminoglycoside prescription) were associated with outcome (data not shown). 


\section{DISCUSSION}

We studied here the features of $L m$-associated endovascular infections. They present as vascular infection and endocarditis. To our knowledge, $L m$-associated endovascular infections have only been reported as isolated cases reports so far. This study of 71 patients is the first to report a series of cases, which corresponds to all incident cases declared at the national level during a 25 -year period. It is also the first study that reports a detailed analysis of associated $\mathrm{Lm}$ isolates. The retrospective nature of the study is its main limitation, although cases were prospectively declared and individually reviewed according to a pre-established check-list. Although the French mandatory system is proven highly effective, with an exhaustiveness evaluated above $87 \%$ (33), one cannot exclude an under-reporting of such an atypical presentation of listeriosis, that might be considered by default as isolated septicemia, the most frequent clinical presentation. Also, the retrospective methodology based on record review limited our ability to evaluate $L m$-related mortality.

Several important conclusions can be drawn from this work. First, predisposing factors for $\mathrm{Lm}$ endocarditis and $L m$ vascular infections are similar and combine older age (median 75 years), comorbidities (reported in 93\%, including immunosuppressive comorbidities in 50\%) and prosthetic devices (reported in 46\%). Patients with vascular infections do not differ from those with infected aortic aneurysms or endograft infections (mean age of 63 to 71 years and immunosuppressive comorbidities rates of 39 to $70 \%$ from published series $(9,10,34))$. Patients with endocarditis are much older than previously reported (mean age of 50-65 years in a review of 68 compiled cases from 1985 to 2000 (19)). They are also much older than patients with endocarditis involving other bacteria (mean age of 57 years in the ICE cohort (35)). As one would expect, they also exhibit a higher rate of immunosuppressive comorbidities (55\% versus $36 \%$ in ICE cohort (35)). However, patients with endovascular listeriosis exhibit twice less immunosuppressive comorbidities than those with $\mathrm{Lm}$ septicemia from the MONALISA cohort (50\% versus 97\%) (31). Other factors than immunosuppression might therefore contribute to the pathogenesis of $\mathrm{Lm}$ endovascular infections, including the presence of prosthetic devices, which may favor the revelation of an otherwise asymptomatic $L m$ bacteremia. $L m$ endocarditis involved such devices in $72 \%$ of cases, versus $28 \%$ in the ICE cohort $(p<0.0001)$. Altogether, the presence of prosthetic devices, either valvular, intracardiac or vascular, is associated with a significant 
increase of endocarditis or vascular infection in case of bacteremia (OR 6.5, 95\% CI 3.6-11.8). This has significant clinical implications and suggests that patients with $\mathrm{Lm}$-bacteremia reporting such devices should undergo systematic evaluation for Lm-associated prosthetic infection, as this condition requires specific management, including possible surgery. Given the OR of vascular infections in patients with bacteremia and prosthetic devices, as much as 175 patients might have suffered from endovascular listeriosis during the study period, including 105 misclassified as $\mathrm{Lm}$-associated bacteremia who might have required specific management.

Vascular infections exhibited milder presentation than caused by other pathogens (typically Staphylococcus aureus, Enterobacteriaceae including Salmonella sp. and anaerobic flora), with lower rates of fever and local pain $(51 \%$ and $29 \%$, versus respectively $66-89 \%$ and $65-85 \%$ of cases in infections involving other pathogens) $(22,34,36,37)$. This is in line with the limited systemic inflammation associated with invasive listeriosis (31). Infrarenal involvement and hemorrhagic shock rates did not differ from those reported in other bacterial aneurysmal infections $(22,36,37)$. Endocarditis also exhibited distinctive features: they never involved right-sided valves; no skin lesion was reported nor any of the classical endocarditis signs like Roth's spots or enlarged spleen (38). Except for one patient with arthritis, septic emboli exclusively involved the central nervous system (CNS), with a dissemination rate of $17 \%$, in the range reported for staphylococcus- or streptococcus -associated endocarditis $(35,38)$. Endovascular infection was not associated with specific $L m$ clone(s), and $L m$ genome sequence diversity mirrored that of the general distribution of the isolates causing sporadic listeriosis cases.

Mortality associated with aneurysmal infections or prosthetic tubes infections was in the range reported for other pathogens ( $12 \%$ versus $11-21 \%$, respectively) $(22,34,36,37)$. Median time to diagnosis was overall short (7 days), with most organisms isolated on surgical specimens; this probably reflects prompt surgical management, leading to timely detection and management of the cases.

In contrast, patients with endocarditis exhibited a $41 \%$ mortality, twice higher than reported for endocarditis related to other pathogens (18\% in the ICE cohort), despite similar ranges of surgical therapy (38 versus 48\%) (39). Mortality was 10 times higher than in Streptococcus-associated endocarditis $(4-8 \%)(40,41)$ and in the range reported with Staphylococcus aureus $(27-34 \%)(35,41)$. In contrast to a previous report, mortality rates for endovascular infections were stable over time (19). 
There are no specific therapeutic guidelines for $L m$-endocarditis or vascular infections (7, 42, 43), and most patients received a combination of amoxicillin and aminoglycoside, a regimen supported by the demonstrated bactericidal effect of this combination. All patients with vascular listeriosis experienced surgery.

In vitro studies have evidenced that $L m$ can infect endothelial cells $(44,45)$, and multiply intracellularly (46). Endothelial cells may also be infected by cell-to cell spread from infected monocytes (44). Interestingly, invasion of cardiac cells has been reported (47) (48). This cohort however suggests that in most cases, $L m$-associated endovascular infections require additional conditions to develop, namely the presence of prosthetic devices.

In conclusion, Lm-associated endocarditis, aneurysmal and prosthetic tubes infections are rare but clinicians should be aware of the existence of this severe specific complication, in particular in patients with vascular or cardiac prostatic devices and $L m$-associated septicemia. They should be carefully evaluated for possible $L m$-associated endovascular infections, so that active combined antimicrobial therapy and surgical management can be prescribed timely and appropriately. 


\section{Acknowledgements}

We thank Dr. Isabelle Serre (Gui Chauliac University Hospital, Montpellier, France), Dr. Valérie Hervieu (Edouard Herriot University Hospital, Lyon, France), Dr. Beatrice Luciani-Laillou (Périgueux, France) and Dr. Luc Marcellin (Hautepierre University Hospital, Strasbourg, France), David Hardy and Magali Tichit (Experimental Neuropathology Unit, Institut Pasteur, Paris) for their contribution to histopathology studies, as well as Giulia Nigro (Molecular Microbial Pathologenesis Unit, Institut Pasteur, Paris).

This study received financial support from Institut Pasteur, Inserm and Santé Publique France.

\section{The Listeriosis endovascular infections study group}

Drs. Alban Le Monnier, François Philippart (Hôpital Saint Joseph, Paris), Julien Galley (Clinique du Pot de Chaume Montauban), Lucile Mendes, Dimitar Balezdrov, Véronique Kostek, Alain Le Coustumier (CH Cahors), Pierre Cahen, Gilles Dreyfus, Isabelle Di Centa (Hôpital Foch, Suresnes), Olivier Join-Lambert, Paul Milliez (CHU Caen), Sylvie Charachon, Charles Arich (CHU Nîmes), Jérôme Etienne, Sébastien Lepage, Valérie Hervieu (CH E Herriot Lyon), Jacob Eliet, Philippe Gaudart, Philippe Vande Perre, Robert Grolleau, Edmond Escuret, Hélène Darbas, Bruno Souche, Christian Carrière, Thomas d'Annoville, Isabelle Serre (CHU Montpellier), Etienne Carbonelle, Yves Cohen (CHU Avicenne, Bobigny), Philippe Despins, Didier Lepelletier (CHU Nantes), François Gabriel (CH Macon), Clémentine Massip, Didier Carrie (CHU Toulouse), Yann Leveneur (CH Tarbes), Jacques Vaucel, Sylvain Bodi, Benoit Moquet, Claude Beuscart, Rasha Wardi (CH Saint Brieuc), Mohammad Koussa (CH Armentières), Marc Maynadie, Lionel Piroth, Frederic Dalle, Philippe Charve (CHU Dijon), Uriel Sebbag (CCN, Saint Denis), Max Maurin, Vincent Dutheil (CHU Grenoble), Annie Vermersch-Langlin (CH Valenciennes), Henri Warembourg, Nadine Lemaitre, René Courcol, Caroline Blazejewski (CHRU Lille),Thierry Dyomédéa, Laurent Varenne (GHM Les Portes Sud Lyon), Manuel Bacrot (CH Saint Martin Boulogne), Eric Senneville, Olivier Robineau, Pierre Patoz (CHU Tourcoing), Jean-François Muir, Loic Favennec, Jean-François Lemeland, Gérard Oksenhendler, Jean-François Lemeland, Benoit Weber (CHU Rouen), Pierre Lureau, Eric Thomas (CH Niort), Monique Melon Henri Amigues (CH Pau), Yann Le Paul (CH Vendée), François Leroux ( $\mathrm{CH}$ Sud Réunion), Jacques 
Guilloteau, Didier Lefant (CH Saint Louis, La Rochelle), Christophe Bros (SEL Cardiomaine, Le Mans), Abderrazak El Yamani (CH Blois), Jean-Paul Broustet, Cécile Bébéar (CHU Bordeaux), Jean-Paul Reboud (GHM Grenoble), Olivier Martinet, Benoît Jauhlac, Yves Hansmann, Luc Marcellin (NHC, Strasbourg), Marc Ferec, Julie Gorret (CH Pays de Morlaix, Brest), Jordan Leroy, Stéphalie Delelis (CHU Amiens), Paul-Louis Woerther, Patrick Nataf (CHU Bichat, Paris), Paul Aguilar, Béatrice Luciani-Laillou (CH Périgueux), Raymond Ruimy, Viviane Queyrel, Laurent Jacq (CHU Nice), Souad Silhadi, Agnès Vinay (CH Métropole Savoie, Chambéry), Alain Brusset (Clinique Ambroise Paré Boulogne), Anne Mimgam, Mathieu Dupont (CH Saint Malo), Bruno Chatillon (Polyclinique du Sidobre Castres), Elani Lapis, Emile Ducroux (CHU Besançon), Vincent Jarlier, Laurent Chiche (CHU Pitié Salpétrière, Paris), Béatrice Pangon, Clément Charbonnel (CH Versailles), Hamid Berbiche, Alain Marmonier (CH Le Mans), Vincent Jarlier, Laurent Chiche (CHU Pitié Salpétrière, Paris), Anthony Texier Luciani Sylvestre (CH Macon), Bruno Pozzetto (CHU Saint Etienne), Caroline Piau, Elodie Clochard (CHU Rennes), Mathieu Hermier (Clinique d'Occitanie, Les Mureaux), Isabelle Goidin (CH Calais), Benoit Cremillieux (HPL Saint Etienne). 


\section{REFERENCES}

1. de Valk H, Tourdjman, M., Leclercq, A., Maury, M., Moura, A., Laurent, E., ChenalFrancisque, V., Goulet, V., Brisse, S., and Lecuit, M., editor Changes in epidemiology and surveillance of listeriosis in France. International Symposium On Problems of Listeriosis; 2016; Paris.

2. Godshall CE, Suh G, Lorber B. Cutaneous listeriosis. J Clin Microbiol. 2013;51(11):3591-6.

3. Charlier C, Leclercq A, Cazenave B, Desplaces N, Travier L, Cantinelli T, et al. Listeria monocytogenes-associated joint and bone infections: a study of 43 consecutive cases. Clin Infect Dis. 2012;54(2):240-8.

4. Charlier C, Fevre C, Travier L, Cazenave B, Bracq-Dieye H, Podevin J, et al. Listeria monocytogenes-associated biliary tract infections: a study of 12 consecutive cases and review. Medicine. 2014;93(18):e105.

5. Danion F, Maury MM, Leclercq A, Moura A, Perronne V, Leotard S, et al. Listeria monocytogenes isolation from urine: a series of 15 cases and review. Clin Microbiol Infect. 2017.

6. Chersich MF, Takkinen J, Charlier C, Leclercq A, Adams PE, Godbole G, et al. Diagnosis and Treatment of Listeria monocytogenes Endophthalmitis: A Systematic Review. Ocul Immunol Inflamm. 2017:1-10.

7. Brouqui P, Raoult D. Endocarditis due to rare and fastidious bacteria. Clin Microbiol Rev. 2001;14(1):177-207.

8. Antolin J, Gutierrez A, Segoviano R, Lopez R, Ciguenza R. Endocarditis due to Listeria: description of two cases and review of the literature. Eur J Intern Med. 2008;19(4):295-6.

9. Brossier J, Lesprit P, Marzelle J, Allaire E, Becquemin JP, Desgranges P. New bacteriological patterns in primary infected aorto-iliac aneurysms: a single-centre experience. Eur J Vasc Endovasc Surg. 2010;40(5):582-8.

10. Oderich GS, Panneton JM, Bower TC, Cherry KJ, Jr., Rowland CM, Noel AA, et al. Infected aortic aneurysms: aggressive presentation, complicated early outcome, but durable results. J Vasc Surg. 2001;34(5):900-8.

11. Boulloche N, Slaoui T, Viguier A, Glock Y, Chabanon G, Rigal M, et al. Ischemic cerebral attacks due to a pseudo-aneurysm of the internal carotid artery with Listeria monocytogenes. J Neurol. 2007;254(1):122-3.

12. Murphy K, Al-Jundi W, Nawaz S. Mycotic aneurysms of the abdominal aorta due to Listeria monocytogenes. Int J Surg Case Rep. 2013;4(7):626-8.

13. Bal A, Schonleben F, Agaimy A, Gessner A, Lang W. Listeria monocytogenes as a rare cause of mycotic aortic aneurysm. J Vasc Surg. 2010;52(2):456-9.

14. Paccalin M, Amoura Z, Brocheriou I, Hernigou A, Delangle MH, Lecso Bornet M, et al. [Infectious aneurysm due to Listeria monocytogenes: a new case and review of the literature]. Rev Med Interne. 1998;19(9):661-5.

15. Ciceri G, Gori M, Bianchi S, Corrado G, Panisi P, Papa A, et al. Molecular evidence of Listeria monocytogenes infection relapse in a severe case of endocarditis. JMM Case Rep. 2017;4(9):e005115.

16. Rahmati E, Jan Geiseler P, She RC. Lower extremity mycotic aneurysm in a patient with Listeria monocytogenes - associated prosthetic valve endocarditis. JMM Case Rep. 2017;4(5):e005095.

17. Valckx W, Lutgens SPM, Haerkens-Arends HE, Barneveld PC, Beutler JJ, Hoogeveen EK. Listeria Endocarditis: A Diagnostic Challenge. J Investig Med High Impact Case Rep. 2017;5(2):2324709617698995.

18. Gunst JD, Jensen-Fangel S. A mycotic abdominal aortic aneurysm caused by Listeria monocytogenes in a patient with HIV infection. BMJ Case Rep. 2014;2014. 
19. Fernandez Guerrero ML, Rivas P, Rabago R, Nunez A, de Gorgolas M, Martinell J. Prosthetic valve endocarditis due to Listeria monocytogenes. Report of two cases and reviews. Int J Infect Dis. 2004;8(2):97-102.

20. Goulet V, Jacquet C, Martin P, Vaillant V, Laurent E, de Valk H. Surveillance of human listeriosis in France, 2001-2003. Euro Surveill. 2006;11(6):79-81.

21. Reddy DJ, Shepard AD, Evans JR, Wright DJ, Smith RF, Ernst CB. Management of infected aortoiliac aneurysms. Arch Surg. 1991;126(7):873-8; discussion 8-9.

22. Hsu RB, Chen RJ, Wang SS, Chu SH. Infected aortic aneurysms: clinical outcome and risk factor analysis. J Vasc Surg. 2004;40(1):30-5.

23. Durack DT, Lukes AS, Bright DK. New criteria for diagnosis of infective endocarditis: utilization of specific echocardiographic findings. Duke Endocarditis Service. Am J Med. 1994;96(3):200-9.

24. Li JS, Sexton DJ, Mick N, Nettles R, Fowler VG, Jr., Ryan T, et al. Proposed modifications to the Duke criteria for the diagnosis of infective endocarditis. Clin Infect Dis. 2000;30(4):633-8.

25. Thouvenot P, Vales G, Bracq-Dieye H, Tessaud-Rita N, Maury MM, Moura A, et al. MALDI-TOF mass spectrometry-based identification of Listeria species in surveillance: A prospective study. J Microbiol Methods. 2018;144:29-32.

26. Bille J, Catimel B, Bannerman E, Jacquet C, Yersin MN, Caniaux I, et al. API Listeria, a new and promising one-day system to identify Listeria isolates. Appl Environ Microbiol. 1992;58(6):1857-60.

27. Moura A, Tourdjman M, Leclercq A, Hamelin E, Laurent E, Fredriksen N, et al. RealTime Whole-Genome Sequencing for Surveillance of Listeria monocytogenes, France. Emerg Infect Dis. 2017;23(9):1462-70.

28. Ragon M, Wirth T, Hollandt F, Lavenir R, Lecuit M, Le Monnier A, et al. A new perspective on Listeria monocytogenes evolution. PLoS Pathog. 2008;4(9):e1000146.

29. Doumith M, Buchrieser C, Glaser P, Jacquet C, Martin P. Differentiation of the major Listeria monocytogenes serovars by multiplex PCR. J Clin Microbiol. 2004;42(8):3819-22.

30. Moura A, Criscuolo A, Pouseele H, Maury MM, Leclercq A, Tarr C, et al. Whole genome-based population biology and epidemiological surveillance of Listeria monocytogenes. Nat Microbiol. 2016;2:16185.

31. Charlier C, Perrodeau E, Leclercq A, Cazenave B, Pilmis B, Henry B, et al. Clinical features and prognostic factors of listeriosis: the MONALISA national prospective cohort study. Lancet Infect Dis. 2017;17(5):510-9.

32. Maury MM, Tsai YH, Charlier C, Touchon M, Chenal-Francisque V, Leclercq A, et al. Uncovering Listeria monocytogenes hypervirulence by harnessing its biodiversity. Nat Genet. 2016;48(3):308-13. .

33. de Valk H, Tourdjman, M., Leclercq, A., Maury, M., Moura, A., Laurent, E., ChenalFrancisque, V., Goulet, V., Brisse, S., and Lecuit, M., editor Changes in epidemiology and surveillance of listeriosis in France. International Symposium On Problems of Listeriosis; 2016; Paris: Institut Pasteur.

34. Smeds MR, Duncan AA, Harlander-Locke MP, Lawrence PF, Lyden S, Fatima J, et al. Treatment and outcomes of aortic endograft infection. J Vasc Surg. 2016;63(2):332-40.

35. Murdoch DR, Corey GR, Hoen B, Miro JM, Fowler VG, Jr., Bayer AS, et al. Clinical presentation, etiology, and outcome of infective endocarditis in the 21st century: the International Collaboration on Endocarditis-Prospective Cohort Study. Arch Intern Med. 2009;169(5):463-73.

36. Brossier J, Lesprit P, Marzelle J, Allaire E, Becquemin JP, Desgranges P. New bacteriological patterns in primary infected aorto-iliac aneurysms: a single-centre experience. Eur J Vasc Endovasc Surg. 2010;40(5):582-8. 
37. Oderich GS, Panneton JM, Bower TC, Cherry KJ, Jr., Rowland CM, Noel AA, et al. Infected aortic aneurysms: aggressive presentation, complicated early outcome, but durable results. J Vasc Surg. 2001;34(5):900-8.

38. Cahill TJ, Prendergast BD. Infective endocarditis. Lancet. 2016;387(10021):882-93.

39. Amodeo MR, Clulow T, Lainchbury J, Murdoch DR, Gallagher K, Dyer A, et al. Outpatient intravenous treatment for infective endocarditis: safety, effectiveness and one-year outcomes. J Infect. 2009;59(6):387-93.

40. Chu VH, Cabell CH, Benjamin DK, Jr., Kuniholm EF, Fowler VG, Jr., Engemann J, et al. Early predictors of in-hospital death in infective endocarditis. Circulation. 2004;109(14):1745-9.

41. Hill EE, Herijgers P, Claus P, Vanderschueren S, Herregods MC, Peetermans WE. Infective endocarditis: changing epidemiology and predictors of 6-month mortality: a prospective cohort study. Eur Heart J. 2007;28(2):196-203.

42. Revest M, Camou F, Senneville E, Caillon J, Laurent F, Calvet B, et al. Medical treatment of prosthetic vascular graft infections: Review of the literature and proposals of a Working Group. Int J Antimicrob Agents. 2015;46(3):254-65.

43. Wilson WR, Bower TC, Creager MA, Amin-Hanjani S, O'Gara PT, Lockhart PB, et al. Vascular Graft Infections, Mycotic Aneurysms, and Endovascular Infections: A Scientific Statement From the American Heart Association. Circulation. 2016;134(20):e412-e60.

44. Drevets DA. Listeria monocytogenes infection of cultured endothelial cells stimulates neutrophil adhesion and adhesion molecule expression. J Immunol. 1997;158(11):5305-13.

45. Parida SK, Domann E, Rohde M, Muller S, Darji A, Hain T, et al. Internalin B is essential for adhesion and mediates the invasion of Listeria monocytogenes into human endothelial cells. Mol Microbiol. 1998;28(1):81-93.

46. Greiffenberg L, Goebel W, Kim KS, Weiglein I, Bubert A, Engelbrecht F, et al. Interaction of Listeria monocytogenes with human brain microvascular endothelial cells: InlBdependent invasion, long-term intracellular growth, and spread from macrophages to endothelial cells. Infect Immun. 1998;66(11):5260-7.

47. McMullen PD, Freitag NE. Assessing bacterial invasion of cardiac cells in culture and heart colonization in infected mice using Listeria monocytogenes. J Vis Exp. 2015(99):e52497. 48. Alonzo F, 3rd, Bobo LD, Skiest DJ, Freitag NE. Evidence for subpopulations of Listeria monocytogenes with enhanced invasion of cardiac cells. J Med Microbiol. 2011;60(Pt 4):42334. 
Table 1. Epidemiological characteristics of the 71 patients with endovascular listeriosis

\begin{tabular}{|c|c|c|c|c|}
\hline & $\begin{array}{c}\text { Vascular } \\
\text { infection * } \\
n=42(\%)\end{array}$ & Endocarditis * & $n=71(\%)$ & $\mathbf{P} H$ \\
\hline Sex ratio, male/total & 0,91 & 0,69 & 0,82 & 0.01 \\
\hline Median age [range] & $74[53-91]$ & 77 [46-92] & 75 [46-92] & NS \\
\hline \multicolumn{5}{|l|}{ Associated conditions } \\
\hline Median number of associated conditions [range] & $2[0-4]$ & $2[1-6]$ & $2[0-6]$ & NS \\
\hline Presence of a prosthetic device & $12 / 42(29)$ & $21 / 29(72)$ & $33 / 71(46)$ & $<0.001$ \\
\hline Vascular device & $12 / 42(29)$ & $1 / 29(3)+$ & $13 / 71(18)+$ & \\
\hline Heart valve device & $0 / 42(0)$ & $18 / 29(62)+$ & $18 / 71(25)+$ & \\
\hline Other device & $0 / 42(0)$ & $3 / 29(10)$ & $3 / 71(4)$ & \\
\hline Immunosuppressive condition(s) & $19 / 41(46)$ & $16 / 29(55)$ & $35 / 70(50)$ & NS \\
\hline Diabetes & $8 / 41(20)$ & $4 / 29(14)$ & $12 / 70(17)$ & NS \\
\hline Neoplasia & $5 / 41(12)$ & $7 / 29(24)$ & $12 / 70(17)$ & NS \\
\hline Hemopathy $\ddagger$ & $2 / 41(4)$ & $5 / 29(17) * *$ & $7 / 70(10)$ & - \\
\hline Recent/ongoing cancer $\S$ & $4 / 41(10)$ & $3 / 29(10) * *$ & $7 / 70(10)$ & - \\
\hline Rheumatoid arthritis & $4 / 41(10)$ & $3 / 29(10)$ & $7 / 70(10)$ & NS \\
\hline Other autoimmune disease $+\dagger$ & $4 / 41(10)$ & $2 / 29(7)$ & $6 / 70(8)$ & NS \\
\hline Chronic renal failure & $4 / 41(10)$ & $6 / 29(21)$ & $10 / 70(14)$ & NS \\
\hline Cirrhosis & $1 / 41(2)$ & $2 / 29(7)$ & $3 / 70(4)$ & NS \\
\hline Concomitant immunosuppressive therapy & $4 / 41(10)$ & $4 / 29(14)$ & $8 / 70(11)$ & NS \\
\hline Corticosteroids & $4 / 41(10)$ & $3 / 29(10)$ & $7 / 70(10)$ & NS \\
\hline Anti-TNF biotherapy & $3 / 41(7)$ & $2 / 29(7)$ & $5 / 70(7)$ & NS \\
\hline Methotrexate & $2 / 41(5)$ & $0 / 29(0)$ & $2 / 70(3)$ & NS \\
\hline Other & 0 & $2 / 29(7)$ & $2 / 70(3)$ & NS \\
\hline Carboplatin + docetaxel & 0 & $1 / 29(3)$ & $1 / 70(1)$ & NS \\
\hline Ofatumumab & 0 & $1 / 29(3)$ & $1 / 7(1)$ & NS \\
\hline Other non-immunosuppressive condition(s) & $36 / 41(88)$ & $27 / 29(93)$ & $63 / 70(90)$ & NS \\
\hline Cardiovascular disease & $28 / 41(68)$ & $25 / 29(86)$ & $53 / 70(76)$ & NS \\
\hline Other miscellaneous conditions & $9 / 41(22)$ & $6 / 29(21)$ & $15 / 70(21)$ & NS \\
\hline \multicolumn{5}{|c|}{$\begin{array}{l}\text { Solid organ cancers consisted in colorectal adenocarcinoma, prostate adenocarcinoma ( } \mathrm{n}=2 \text {, each, } 3 \%) \text {, lung carcinoma, hepatocellular } \\
\text { carcinoma and squamous cell carcinoma }(\mathrm{n}=1,1 \% \text {, each). } \\
\text { ** One patient had both Waldenstrom's macroglobulinemia and lung cancer treated by chemotherapy. } \\
++ \text { Other autoimmune diseases included: dermatomyositis }(\mathrm{n}=2,3 \%) \text {, Crohn disease, Gougerot-Sjogren syndrome, anti-phospholipid } \\
\text { syndrome and undetermined autoimmune disease }(\mathrm{n}=1,1 \% \text { each). } \\
\text { \#+ Student t test or Fisher's exact test was performed between the vascular infections and endocarditis groups. }\end{array}$} \\
\hline
\end{tabular}


Table 2. Clinical characteristics of 44 patients with vascular listeriosis

\begin{tabular}{|c|c|}
\hline Clinical Characteristics & Value (\%) \\
\hline Type of infection & $\mathrm{n}=44 *$ \\
\hline Native artery $(\%)$ & $30 / 44(68)$ \\
\hline Aorta (infra-; supra-renal) & $22(18 ; 4)$ \\
\hline Iliac artery & 4 \\
\hline Femoral artery & 1 \\
\hline Popliteal artery & 3 \\
\hline Prosthetic $(\%)$ & $14 / 44(32)$ \\
\hline Femoro-popliteal & 6 \\
\hline Ascendant aorta & 1 \\
\hline Descendant aorta & 7 \\
\hline \multicolumn{2}{|l|}{ Clinical features } \\
\hline Median time from first symptom to diagnosis in days [range] & $7[0-107](n=37)$ \\
\hline Fever $(\%)$ & $20 / 39(51)$ \\
\hline Rupture (\%) & $25 / 42(60)$ \\
\hline Rupture with hemorrhagic shock (\%) & $6 / 42(14)$ \\
\hline Bleeding $(\%) \dagger$ & $3 / 42(7)$ \\
\hline Local pain without rupture (\%) & $12 / 42(29)$ \\
\hline Other $(\%) \ddagger$ & $10 / 42(24)$ \\
\hline Asymptomatic $(\%)$ & $3 / 42(7)$ \\
\hline \multicolumn{2}{|l|}{ Laboratory findings } \\
\hline Leucocyte count, median [range] & $9,480 / \mathrm{mm} 3[4,790-23,200](\mathrm{n}=30)$ \\
\hline Hyperleukocytosis $>10,000 / \mathrm{mm} 3(\%)$ & $10 / 30(33)$ \\
\hline Neutrophils count, median [range] & $7,200 / \mathrm{mm} 3[3,200-15,238](\mathrm{n}=21)$ \\
\hline Lymphocyte count, median [range] & $909 / \mathrm{mm} 3[0-4,293](\mathrm{n}=21)$ \\
\hline Monocytes count, median [range] & $585 / \mathrm{mm} 3[190-900](\mathrm{n}=18)$ \\
\hline C-reactive protein, median [range] & $96 \mathrm{mg} / \mathrm{L}[5-250](\mathrm{n}=20)$ \\
\hline \multicolumn{2}{|l|}{ Microbiological data } \\
\hline Blood culture(s) performed $(\%)$ & $27 / 42(64)$ \\
\hline Positive blood culture if performed (\%) & $10 / 27(37)$ \\
\hline Positive per-operative specimen (\%) & $43 / 44(98) \S$ \\
\hline Intensive care management $(\%)$ & $44 / 44(100)$ \\
\hline Median follow-up after antibiotic completion (days), [range] & $45[5-3650](n=42)$ \\
\hline Infection-related in-hospital death & $5 / 42(12)$ \\
\hline
\end{tabular}

\footnotetext{
* Among the 44 patients, 2 had both endocarditis and vascular infections

+ Rupture was associated with gastro-intestinal hemorrhage $(n=2)$ or hemoptysis $(n=1)$

$\$$ Limb ischemia $(n=5)$, diarrhea, concomitant skin fistula $(n=2$, each) and L2/L3 spondylodiscitis $(n=1)$

$\S$ One patient had macroscopic per-operative evidence for pus and thrombus at the site of infection: blood culture grew Listeria

monocytogenes but local samples did not.
} 
Table 3. Clinical characteristics of 29 patients with Listeria monocytogenes endocarditis*

\section{Clinical Characteristics}

\section{Timing of infection}

Acute $(<1$ month from first symptom) $(\%)$

Chronic ( $\geq 1$ month from first symptom) (\%)

\section{Type of infection}

Prosthetic valve $(\%)$

Native valve $(\%)$

Mono-ventricular assist device $(\%)$

$3 / 29(10)$

\section{Involved valves}

Aortic

$16 / 26(62)$

Mitral

Aortic and mitral

\section{Clinical features}

Median time from first symptom to diagnosis in days [range]

Fever (\%)

$8 / 26(31)$

$2 / 26(8)$

Cardiac failure (\%)

Neurological symptoms (\%)

Concomitant neurolisteriosis (\%)

Other neurological symptoms ${ }^{\ddagger}(\%)$

Other symptoms § (\%)

Intensive care unit management (\%)

\section{Laboratory findings}

Leucocyte count, median [range]

Hyperleukocytosis $>10000 / \mathrm{mm} 3$

Neutrophils count, median [range]

Lymphocytes count, median [range]

Monocytes count, median [range]

C-reactive protein, median [range]

\section{Microbiological data}

Blood culture(s) performed (\%)

Positive blood culture if performed (\%)

Other culture-positive samples (\%)

Prosthetic valvular material infection

Aneurysmal peri-prosthetic pus

Thrombus on the ventricular assistance device

Pacemaker leads

Knee synovial fluid

Cerebrospinal fluid

$26 / 29+(90)$

$7 / 29(24)$

2

$1+$

$1 \dagger$

$1+$ $10[0-75](\mathrm{n}=27)$

$26 / 29(90)$

$13 / 29(45)$

$7 / 29(24)$

$5 / 29(17)$

$2 / 29(7)$

$8 / 29(28)$

$8 / 20(40)$

$9,100 / \mathrm{mm} 3[2,800-18,600](\mathrm{n}=22)$

$8 / 22(36)$

6900/mm3 [4,200-15,800] ( $\mathrm{n}=18)$

$1,250 / \mathrm{mm} 3[20-4,900](\mathrm{n}=15)$

$810 / \mathrm{mm} 3[200-4,000](\mathrm{n}=15)$

$90 \mathrm{mg} / \mathrm{L}[5-250](\mathrm{n}=25)$ 


\section{Echography findings}

Vegetation $(\%)$

Abscess (\%)

Prosthetic dehiscence without vegetation or abscess (\%)

Thrombus of the mono-ventricular assistance device (\%)

Intensive care management $(\%)$

Mean time for follow-up (days), [range]

$90[8-3650]$

Infection-related in-hospital death (\%)

$12 / 29(41)$

\footnotetext{
* Two patients had both endocarditis and vascular infections

* Other neurological symptoms were: exacerbation of Parkinson disease and subdural hematoma $(\mathrm{n}=1$, each).

$\S$ Other symptoms were: deterioration of the general status and abdominal pain $(n=3$, each), cirrhotic ascites and septic arthritis ( $n=1$, each)

+ Three patients had negative blood cultures but grew L. monocytogenes respectively on the thrombus associated with ventricular assistance device, on the pace maker-leads and on a perianeurysmal purulent collection
} 
Table 4. Treatment and outcome of 71 patients with endovascular listeriosis

\begin{tabular}{|c|c|c|c|c|}
\hline & Vascular infections* & Endocarditis* & Total & $\mathbf{P}+$ \\
\hline Surgery & $42 / 42(100)$ & $11 / 29(38)$ & $51 / 72(72)$ & $<10-4$ \\
\hline Urgent ( $\leq 48 \mathrm{~h}$ after vascular consultation) & $21 / 42(50)$ & NA & & \\
\hline \multicolumn{5}{|l|}{ Antibiotic therapy +} \\
\hline No antibiotic & $0 / 39(0)$ & $1 / 28(4)$ & $1 / 67(1)$ & NS \\
\hline Mono-antibiotherapy & $8 / 39(21)$ & $2 / 28(7)$ & 10/67 (15) & NS \\
\hline Amoxicillin $n=(\%)$ & $6 / 39(15)$ & $2 / 28(7)$ & $8 / 67(12)$ & NS \\
\hline Cotrimoxazole $n=(\%)$ & $1 / 39(3)$ & - & - & - \\
\hline Imipenem $n=(\%)$ & $1 / 39(3)$ & - & - & - \\
\hline Initial bi-antibiotherapy & $31 / 39(79)$ & $25 / 28(89)$ & $56 / 67(84)$ & NS \\
\hline Amoxicillin + aminoglycoside $(\%)$ & $17 / 31(55)$ & $21 / 25(84)$ & $38 / 56(68)$ & 0.02 \\
\hline Amoxicillin + cotrimoxazole (\%) & $5 / 31(16)$ & - & $5 / 56(9)$ & - \\
\hline Amoxicillin + fluoroquinolone (\%) & $3 / 31(10)$ & $1 / 25(4)$ & $4 / 56(7)$ & - \\
\hline Amoxicillin + rifampicin (\%) & 1/31 (3) & - & $1 / 56(2)$ & - \\
\hline Piperacillin + aminoglycoside (\%) & $1 / 31(3)$ & $1 / 25(4)$ & $2 / 56(4)$ & - \\
\hline Imipenem + vancomycin (\%) & $1 / 31(3)$ & - & $1 / 56(2)$ & - \\
\hline Piperacillin + fluoroquinolone (\%) & $1 / 31(3)$ & - & $1 / 56(2)$ & - \\
\hline Vancomycin + aminoglycoside $(\%)$ & 2/31 (6) & $1 / 25(4)$ & $3 / 56(5)$ & - \\
\hline Cotrimoxazole + aminoglycoside $(\%)$ & - & $1 / 25(4)$ & $1 / 56(2)$ & - \\
\hline Initial biotherapy $>5$ days & $19 / 30(63)$ & $15 / 21(71)$ & $34 / 51(67)$ & NS \\
\hline \multicolumn{5}{|l|}{ Subsequent bi-therapy } \\
\hline No change & $24 / 31(77)$ & $17 / 25(68)$ & $40 / 56(71)$ & 0.02 \\
\hline Amoxicillin + cotrimoxazole (\%) & $6 / 31(20)$ & $4 / 25(16)$ & $10 / 56(18)$ & NS \\
\hline Amoxicillin + linezolid (\%) & - & $1 / 25(4)$ & $1 / 56(2)$ & - \\
\hline Amoxicillin alone (\%) & 2/31 (6) & $2 / 25(8)$ & $4 / 56(7)$ & - \\
\hline Cotrimoxazole alone $(\%)$ & - & $1 / 25(4)$ & $1 / 56(2)$ & - \\
\hline Median antibiotics duration in days [range] & $40[6-180](n=34)$ & $32[1-108](n=26)$ & $38[1-108](n=63)$ & NS \\
\hline
\end{tabular}

* Two patients had both endocarditis and vascular infections: they were studied in the endocarditis group

+ Information was available for 26 patients with endocarditis, for 39 patients with vascular infections and for the 2 patients with both endocarditis and vascular infections who were studied within the endocarditis group

\$ Student $t$ test or Fisher's exact test was performed between the vascular infections and endocarditis groups 


\section{Figure Legends}

\section{Figure 1.}

Contrast CT scan showing contained rupture of a $57 \mathrm{~mm}$ aortic aneurysm with layers of extraluminal high density acute hemorrhage (arrow) in the anterior pararenal space consistent with rupture.

\section{Figure 2.}

Phylogeny based on cgMLST profiles of the $70 \mathrm{Lm}$ isolates involved in cardiovascular listeriosis cases. Single-linkage-based clustering was obtained based on the cgMLST allelic profiles, including 1,748 loci of $\mathrm{Lm}$ core genome, as described previously (30). The scale bar indicates the percentage of similarity between cgMLST profiles. Strain names have been simplified to avoid redundancy and should be preceded by CLIP (Collection Listeria of the Institut Pasteur). Lineages, PCR serogroups and MLST clonal complexes are shown on the right. Strains are colored after their clonal complexes.

\section{Figure 3.}

Mitral valve from a patient with Listeria monocytogenes $(\mathrm{Lm})$-associated endocarditis. $\mathrm{Lm}$ was genogrouped as IIb. Valvular endocarditis was characterized by a multifocal to coalescing inflammatory lesion (arrow), fibrin and calcification (arrowhead) (A and B). Lm was detected by anti- $L m$ IHC (Figure S2C-D). Scale bar: $20 \mu \mathrm{m}$. 